\title{
The accuracy of a CT-based bone segmentation technique for measuring the range of motion of the joints in the ankle L Blankevoort ${ }^{* 1,3}$, L Beimers ${ }^{1,3}$, R Jonges ${ }^{2}$, ER Valstar ${ }^{4}$ and GJM Tuijthof ${ }^{1,3}$
}

\author{
Address: ${ }^{1}$ Orthopaedic Surgery, Academic Medical Center, Amsterdam, ${ }^{2}$ Medical Physics, Academic Medical Center, Amsterdam, ${ }^{3}$ Orthopaedic \\ Research Center Amsterdam (ORCA), Academic Medical Center, Amsterdam and ${ }^{4}$ Orthopaedic Surgery, Leiden University Medical Center, Leiden, \\ The Netherlands \\ Email: L Blankevoort* - L.Blankevoort@amc.uva.nl \\ * Corresponding author
}

from Ist Congress of the International Foot \& Ankle Biomechanics (i-FAB) community

Bologna, Italy. 4-6 September 2008

Published: 26 September 2008

Journal of Foot and Ankle Research 2008, I (Suppl I):O34 doi:I0.I I86/I757-I I46-I-SI-O34

This abstract is available from: http://www.jfootankleres.com/content/I/SI/O34

(c) 2008 Blankevoort et al; licensee BioMed Central Ltd.

\section{Introduction}

For measuring the in-vivo range-of-motion of the ankle joints, a semi-automated Computer Tomography based bone contour method (CT/BCM) was developed to determine the three-dimensional position and orientation of the bones. To validate this technique, we hypothesized that the range of motion in the ankle is at least equally accurately measured by Roentgen Stereophotogrammetric Analysis (RSA) as by the CT/BCM technique.

\section{Methods}

Tantalum beads were placed in the distal tibia, talus and calcaneus of one cadaver specimen. With a fixed lower leg, the cadaveric foot was first held in neutral and subsequently loaded in eight different extreme positions. After acquiring a complete CT-scan with the foot in a position, the specimen was moved through the CT gantry, and two $\mathrm{X}$-ray images were made. Bone contour detection was performed as described by Beimers [1], and RSA was performed according to Valstar [2]. The CT/BCM-data sets and RSA-data sets were transformed into the same coordinate system. Helical axis parameters were calculated for tibiotalar and talocalcaneal joint motion from neutral to the extreme positions and between opposite extreme positions. The differences between CT/BCM and RSA were calculated for rotation around, translation along, the position and the direction of the helical axis.

\section{Results}

The difference between the CT/BCM technique and RSA in helical axis position and helical axis rotation was dependent on the amount of rotation (Figure 1). By approximation, this relationship matched the model by Woltring [3]. Compared with RSA, the CT/BCM data registered a RMS difference of 0.26 degree for rotation about the helical axis, and $0.11 \mathrm{~mm}$ translation along the helical axis for tibiotalar motion between opposite extreme foot position. For talocalcaneal motion, these differences were 0.17 degree and $0.23 \mathrm{~mm}$ respectively.

\section{Conclusion}

A cadaver specimen was used instead of a phantom, mimicking the in-vivo situation. A-priori known kinematics could not be applied, but comparison between the two techniques served as a fair estimate of the accuracy of the $\mathrm{CT} / \mathrm{BCM}$ technique. The data suggest that the CT/BCM technique is as accurate or even more accurate than the RSA technique. 


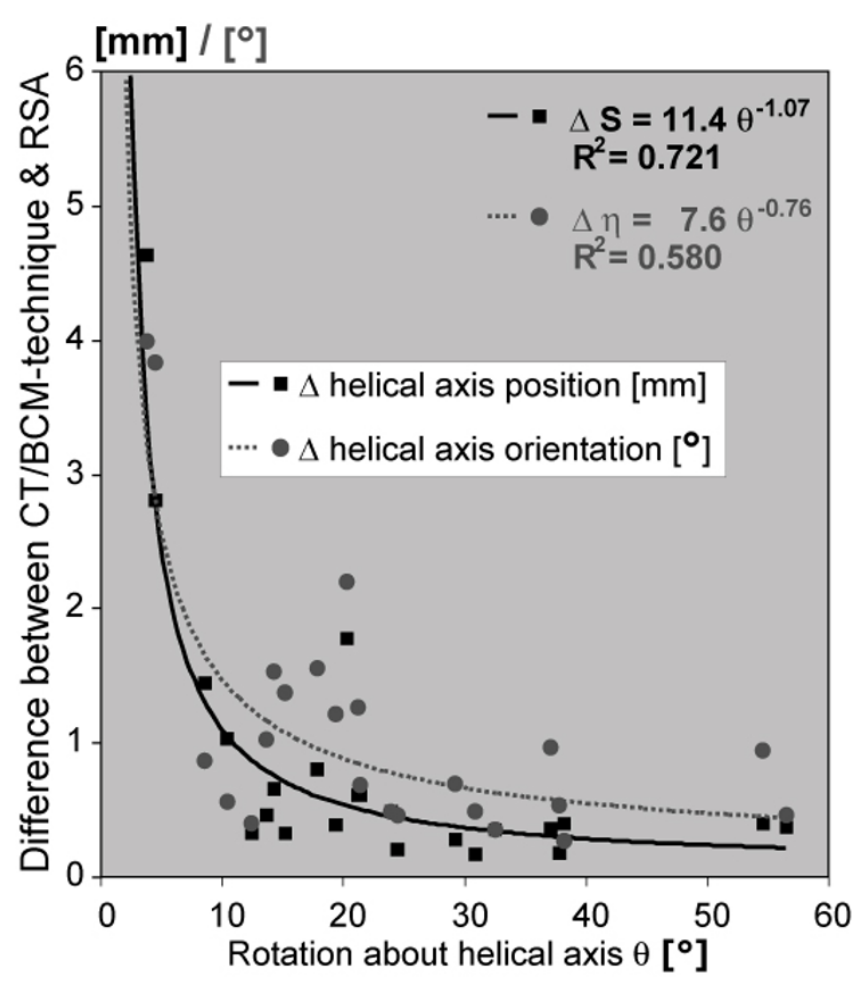

Figure I

Difference in helical axis position and helical axis orientation between the CT technique and RSA technique as functions of the rotation about the helical axis. Data of the tibiotalar and talocalcaneal joints were pooled.

\section{Acknowledgements}

The assistance of Ms. S. Bringmann and Mr. M. Poulus in conducting the experiments is gratefully acknowledged.

\section{References}

I. Beimers L, et al.: . J Biomech. 2008, 41:1390-1397.

2. Valstar ER, et al.: J Biomech 2000, 33:1593-1599.

3. Woltring HJ, et al.: J Biomech 1985, 18:379-389.
Publish with Bio Med Central and every scientist can read your work free of charge

"BioMed Central will be the most significant development for disseminating the results of biomedical research in our lifetime."

Sir Paul Nurse, Cancer Research UK

Your research papers will be:

- available free of charge to the entire biomedical community

- peer reviewed and published immediately upon acceptance

- cited in PubMed and archived on PubMed Central

- yours - you keep the copyright 